\title{
Escritores comprometidos, campo literario y novela total en los años sesenta. Mario Vargas Llosa, lector de Cien años de soledad
}

\author{
Jorge ValenZuela Garcés \\ Universidad Nacional Mayor de San Marcos \\ jorgevalenzuela4@hotmail.com
}

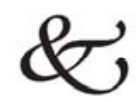

\begin{abstract}
Resumen
El proyecto de "novela total" que concibieron y llevaron a la práctica connotados integrantes del "boom" de la novela hispanoamericana tuvo extraordinarias muestras en textos como Cien años de soledad o La casa verde. En este estudio nos ocupamos de describir el campo literario de los años sesenta y el modo en que este influye, a través de la figura del compromiso, en las demandas al escritor-intelectual de izquierda sobre la necesidad de proyectar, en los textos literarios, una imagen integral del proceso histórico y social del continente. El análisis se centra en la forma en que Vargas Llosa construye, a partir del análisis de una novela como Cien años de soledad, el proyecto de la novela total y el modo en que la novela del escritor colombiano representó esta totalidad respondiendo a las demandas del campo literario en un contexto marcado por un discurso que entonces explicaba la situación de retraso de nuestro continente debido a la dependencia del imperialismo.
\end{abstract}

Palabras claves: Mario Vargas Llosa, novela total, campo intelectual, campo literario.

\begin{abstract}
Abtsract
The project of "novela total", that conceived and put into practice notorious members of the "boom" of the Latin American novel have extraordinary examples in texts such as One hundred years of solitude or The green house. In this study, we took care to describe the literary field of the sixties and how it influences the demands on the writer-intellectual
\end{abstract}




\begin{abstract}
left, especially with regard to the need to project in literary texts a comprehensive picture of the historical process and social development of the continent. The analysis focuses on the manner in which Vargas Llosa constructs, from the analysis of a novel One hundred years of solitude, a novel model of the novela total and the way in which the novel of the colombian writer represented the whole responding to demands the literary field in a context marked by a speech which then explained the situation of our continent delay due to the dependence on imperialism.

Key words: Mario Vargas Llosa, Total novel, Interlectual field, Literary field.
\end{abstract}

\title{
Campo intelectual durante los años sesenta en Hispanoamérica
}

Una de las características del campo intelectual hispanoamericano durante los años sesenta fue que estableció, a través de la obra de sus escritores y de la posición de sus instituciones culturales, una firme resistencia tanto al poder político y económico del capitalismo (en un contexto marcado por las dictaduras y por la injerencia norteamericana en el continente) como al poder de la Iglesia, considerado como su aliado histórico.

Como principio general, esta actitud antiburguesa (como en la Francia de mediados del siglo XIX, salvando las distancias) propició tomas de posición entre críticos y escritores que se formalizaron a través de ciertas filiaciones y solidaridades en torno a la Revolución Socialista como medio para la transformación de la sociedad. Todo esto en un momento en el que la experiencia revolucionaria de Cuba había mostrado las posibilidades de instaurar un mundo más justo en América Latina.

La revolución cubana generó en los escritores del "boom" la necesidad de responder a las demandas de un público joven que empezaba, desde su acceso a las universidades, a preguntarse por la identidad y el destino de América Latina y por el modo de consolidar lo que Cuba había logrado algunos años antes. Estas dos demandas, que el campo intelectual hispanoamericano procesa a través de sus críticos y escritores, configuran el perfil del llamado intelectual comprometido de izquierda y le otorga sentido a su papel como tal. Sumemos a esto, el impulso o la voluntad en muchos de los intelectuales de la época de llevar a la realidad el cambio a partir de una concepción colectivista del mundo en la que los países del continente americano establecían o desarrollaban lazos de hermandad cuya naturaleza los convertía en parte de una sola patria, la latinoamericana.

El campo intelectual latinoamericano se constituye fundamentalmente en un campo de encuentro, o mejor dicho se dinamiza, inicialmente, de es modo. Es 
un campo en el que las convocatorias, reuniones, foros, congresos, simposios, mesas redondas y encuentros de escritores van permitiendo que una suma de voluntades y pareceres a favor de la integración continental se constituya en la base de lo que luego sería la patria latinoamericana, sobre la cual escribirían nuestros narradores. Es así como se formula un único e irrenunciable destino frente al que todos tienen algo que decir, pero sobre todo construir.

Estas políticas de encuentro buscan y se exigen a sí mismas descubrir la verdadera identidad latinoamericana y parten del supuesto de que esa es una tarea impostergable, realizable y posible sin cuya realización es imposible hablar de la independencia del continente. En este sentido y para apoyar la definitiva emancipación, el campo intelectual de los sesenta consolida imaginariamente el concepto de república literaria, haciendo referencia a un espacio libre y moderno en el que los disfrutes de la nacionalidad se darían a partir de una previa identificación de los intereses estéticos latinoamericanos, intereses que debían ser trabajados en las novelas o ensayos de nuestros escritores. De allí la tarea de escribir una sola novela, la de nuestra liberación frente a la dominación imperialista, aquella que, permitiría fundamentalmente, develar el manto de ignorancia secular que no nos permitió conocernos como continente. Es cierto, sin embargo, que este proyecto consolidado por el campo intelectual, adolecía de ciertas limitaciones, una de las cuales fue desconocer las diferencias culturales de nuestros países incorporados, a través de este proyecto, a una república más imaginada que real.

De otro lado, los encuentros de intelectuales postulan la idea de que es necesario conocerse, establecer alianzas, luchar y crear frentes comunes ante la amenaza del imperialismo norteamericano. De este modo, la mutua ignorancia entre latinoamericanos, la falta de apoyo entre intelectuales identificados con la causa de la revolución o la simple indiferencia frente al subdesarrollo del continente se convierte en nuestro peor enemigo.

Destaquemos, de otro lado, el hecho de que esta dinámica va construyendo, a su modo, el espacio para la profesionalización del escritor en tanto la del escritor se va convirtiendo en una ocupación que no sólo demanda la escritura, sino pronunciamientos, viajes, debates o participar en eventos masivos, situaciones inéditas en nuestro campo intelectual a lo largo del siglo XX. De hecho, en la promoción de escritores del boom se opera el paso definitivo de escritor artista al de escritor intelectual con una agenda de responsabilidades claras relacionadas con la problemática social de la época.

Por todo lo dicho, es el campo intelectual de los sesenta el que consolida la estrecha relación de la política con la literatura y fomenta la imagen del intelectual comprometido con su tiempo y con la causa de la liberación continental. El ejemplo de algunos escritores del "boom" de los sesenta, como 
Carlos Fuentes, es significativo de la importancia que la política tiene para ellos en esos momentos. Fuentes llegó a sostener que le parecía absolutamente impropio hablar en público de algo que no fuera de política.

En efecto, los años sesenta, en los que se consolida esta relación, son el escenario en el que se destaca la importancia de lo político en la vida cotidiana, lo político como esa dimensión en la que la responsabilidad de cada sujeto se hace evidente a través de una fuerte identificación con el cambio social, es decir, con la Revolución Socialista. El campo intelectual latinoamericano se percibe, también, como un escenario en el que los escritores y críticos pueden participar activamente a través de compromisos con causas justiciables vinculadas a problemáticas no necesariamente latinoamericanas.

En el campo intelectual, la importancia de lo político afecta lo literario y lo impregna de sus objetivos y metas. De este modo los textos más importantes de la época sitúan este aspecto en primer plano. Su objetivo es destacar la dimensión pública social de la realidad y asumir el reto de convertir a las novelas en espacios de discusión, en foros en los que los llamados problemas sociales ocupan el primer plano. De hecho, en el contexto de los años sesenta el campo intelectual latinoamericano no solo sufre la influencia de lo político sino que lo configura hasta el punto de que los escritores sólo ganan legitimidad o son consagrados por el público debido a su estrecha identificación con problemas que demandan una toma de posición clara a favor de los desposeídos, convirtiéndose por esa razón en escritores comprometidos.

El campo intelectual influye en el hecho de que los escritores, en este caso los del "boom", llegan a aceptar y entender que lo político es una dimensión esencial de la vida de los latinoamericanos, en tanto permite asignarle a los sujetos sociales una identidad común (la del continente latinoamericano) y la creencia de que el cambio social es impostergable. Por lo tanto las novelas asumen un gran reto: revelar la verdadera identidad latinoamericana, aquella identidad oscurecida por la dominación histórica del colonialismo, y alentar el cambio para hacer realidad el proyecto socialista que entonces predominaba en el horizonte político. Emir Rodríguez Monegal lo dice del siguiente modo: "A veces se olvida (involuntariamente, tal vez) que el triunfo de la Revolución Cubana es uno de los factores determinantes del "boom". Lo es por la mera fuerza de las circunstancias políticas, que proyectan de golpe, hacia el centro del ruedo político internacional a la pequeña nación (Cuba) de nueve millones de habitantes, y con ella, a un continente olvidado de doscientos millones" (1972:18). 


\section{El campo literario latinoamericano de los años sesenta}

Pierre Bourdieu destaca en su importante libro Las reglas del arte, que el campo literario y artístico se constituyó en Francia hacia mediados del siglo XIX, en abierta oposición a un mundo "burgués" que en ese momento empezaba a manifestarse de forma violenta en los modos de controlar los instrumentos de legitimación literaria a través de una crítica ciertamente degradante e inculta (1995: 95). En ese contexto, el caso de un escritor como Gustave Flaubert ante esa crítica no puede ser más ilustrativo. El juicio que se le sigue por la publicación de Madame Bovary, es una prueba de la injustica y desconocimiento a los que puede llegar un segmento social (el burgués apegado a los modos neoclásicos) frente a lo revolucionario que puede llegar a ser la literatura ante la moral y lo estatuido. El juicio también mostró el modo en que, simultáneamente, se activó el campo político, hecho que, en su momento demostró las intersecciones de estos dos campos y las duras batallas que debieron librar los escritores de entonces para mantener la independencia del campo literario frente a las arbitrariedades del poder político.

Como todo campo intelectual, al decir de Bourdieu, el campo literario “constituye un sistema de líneas de fuerza en el que los agentes o sistemas de agentes que forman parte de él pueden describirse como fuerzas que, al surgir, se oponen y se agregan, confiriéndole su estructura específica en un momento dado del tiempo" (2003:13). En efecto, el campo literario es un campo dialectico marcado por un sistema de relaciones sociales, normalmente opuestas, pero también complementarias, dentro del cual los escritores producen y depositan sus textos en un acto de comunicación eminentemente social. El campo literario está conformado por los propios escritores y sus proyectos creadores, otros artistas, los cenáculos o espacios para la discusión literaria, las academias, la crítica institucionalizada y la que no lo es, los intermediarios entre el artista y el público y el propio público consumidor de literatura.

En el campo literario son relevantes las creencias del escritor o del crítico en tanto creadores, pues a través de ellos se debaten los temas y los problemas que conforman el campo cultural del que provienen las demandas de los lectores. Son ellos los que a través de sus posturas alimentan las oposiciones y las complementaciones estéticas e ideológicas sin las cuales sería imposible conferirle una estructura al campo literario.

La existencia y pertinencia del campo literario no puede entenderse socialmente sin la atención debida a una prerrogativa ganada por el propio campo a medida que fue independizándose de otros espacios como el político y el eclesiástico. Nos referimos a la competencia por la legitimidad literaria que, en el caso de los escritores, depende necesariamente del juicio de la crítica y de 
los lectores. Es la lógica de la legitimidad la que anima y justifica la existencia del campo literario y la que estrecha las relaciones de los escritores y sus proyectos con la sociedad a través de la demanda social de los consumidores de literatura.

En todo proceso de legitimación el campo literario representado por la crítica y la institución literaria realiza una tarea capital relacionada con el proyecto creativo de un escritor id est resolver las contradicciones entre "la necesidad intrínseca de la obra que necesita proseguirse, mejorarse, terminarse y las restricciones sociales que orientan la obra desde fuera" (Bourdieu 2003: 22). Esta tarea supone, desde luego, un juicio objetivo en el que lo esencial es destacar el sentido público del texto y del autor, entendiendo como sentido público de un texto al sentido necesariamente colectivo sobre la verdad y el valor de una obra.

A partir del reconocimiento del valor de una obra (calidad, importancia, representatividad), es decir de su legitimación, el campo literario le asigna al escritor ciertas tareas relacionadas con las demandas sociales del público y con las del propio campo intelectual al cual se debe. Sin la atención debida a estas demandas, el escritor no podría mantener esa vigencia que lo convierte precisamente en un escritor a los ojos del público y de la crítica.

Pues bien, en el contexto de los años sesenta, el campo literario se ve influido por un conjunto de demandas provenientes del campo intelectual a través de la figura del compromiso del escritor, compromiso que, como lo explica Ángel Rama (1964: 4), debía darse a través de la novela en "donde concurren más conflictos" y cuya amplitud permite el tratamiento de problemáticas complejas y de vasta repercusión social. Rama incide, además, en el hecho de que la novela surge entre nosotros en el contexto de nuestra independencia política, con lo cual marca simbólicamente al género como el espacio privilegiado para nuestra liberación ideológica.

Estas razones hacen que la novela se convierta en el espacio al que debían trasladarse los problemas culturales, sociales y las necesidades del continente. Es de ese modo que empieza, en el campo literario, a hablarse de una novela que sea a la vez una interpretación de nuestra historia, una reflexión sobre nuestra identidad, un símbolo de nuestro continente y un espacio de reconocimiento de lo latinoamericano. Cada una de estas demandas desarrolla, por sí misma, un programa, una línea narrativa.

La que finalmente se privilegia en el contexto de los sesenta está referida a la necesidad de escribir una novela esencialmente latinoamericana, alejada de cualquier influencia ajena a los elementos de nuestra tradición nativa. En este sentido se postula la urgente concreción de una ficción que diera cuenta del ser latinoamericano y que nos permitiera descubrir nuestra identidad. En esta postulación se ve comprometida la idea del tratamiento de espacios público 
sociales (colegios, pueblos, ciudades enteras) capaces de referir situaciones abiertas y complejas, de amplia panorámica y con posibilidades de revelar aspectos esenciales de nuestras conformaciones sociales.

La búsqueda de las raíces de la nacionalidad ocupa, también, un lugar central en el campo literario de la época. Para los novelistas del "boom" es importante responder a preguntas en torno al modo en que se han constituido los valores en que se asienta lo nacional. Por ello se ocupan de implementar en sus textos una perspectiva histórica a partir de la cual configuran un arco de acontecimientos cuya articulación, de alguna manera, da cuenta del presente alumbrando el pasado.

A partir de estas dos preocupaciones, el campo literario clausura cualquier demanda ajena a la problemática referida y orienta a los escritores por los caminos de una novelística cercana, en su conformación, al ensayo, a la historia de origen o al propio mito. La novelística latinoamericana se encuentra preparada para tentar la respuesta a las grandes preguntas sociales del momento. Ese desafío, a su modo, ya la impregna de una gran responsabilidad en la que, sin duda, está anclado el afán de totalidad.

\section{Las responsabilidades del escritor-intelectual de izquierda, cam- po intelectual y representación de la totalidad}

"El compromiso del intelectual"1, artículo escrito por Paul Baran a comienzos de los años sesenta, fue uno de los más influyentes de los que se publicaron en Hispanoamérica en torno a ese tema. Lo fue, entre otras cosas, porque el texto describe, con bastante precisión, el lugar que debían ocupar los escritores progresistas en el marco que entonces imponía, entre nosotros, la dinámica de dominación capitalista a través de sus instituciones.

Baran comienza haciendo una diferencia entre el trabajador intelectual y el intelectual propiamente dicho. Sostiene que el intelectual se caracteriza, fundamentalmente, por un genuino interés por el proceso histórico en conjunto, es decir, por todo aquello que afecta al presente y que tiene repercusión en el desarrollo social. Dice Baran que este interés es de tal envergadura que condiciona su pensamiento, sus reflexiones y su propio trabajo.

1 El texto se publicó en la influyente revista Casa de las Américas a comienzo de los años sesenta, años en los que los integrantes de lo que sería el "boom" de la novela, gestaban ideológicamente sus propios discursos en torno a la revolución castrista y al papel de los intelectuales en el proceso del cambio social. 
En ese artículo, Baran sostiene que la función del intelectual en la sociedad es "la de servir de símbolo y recordatorio del hecho fundamental de que las partes, al parecer autónomas, dispares y desarticuladas de la experiencia social bajo el capitalismo- la literatura, el arte, la política, el orden económico, la ciencia, la condición cultural y psíquica del pueblo-pueden ser comprendidas e influidas solamente en la medida en que sean visualizadas como componentes de la totalidad integrante del proceso histórico" (1961: 17).

Para Baran la ideología y la cultura burguesas tienden a la dispersión y son esencialmente fragmentarias en la medida en que segmentan el conocimiento y por ende la conciencia que lo produce. De allí que la tarea central del intelectual sea la de "relacionar las cosas", de establecer vínculos entre ellas y de propiciar el entendimiento de las relaciones interrumpidas entre los elementos del conjunto social. Baran suscribe, como Hegel, que "la verdad es la totalidad". Es, en el fondo, un idealista objetivo porque considera que la conciencia impersonal es la fuente primera del mundo, la cual existe objetivamente como idea absoluta o razón universal, razón que lo articula todo en el concepto de totalidad concreta, concepto que le sirve para comprender, abarcar el mundo. Como buen idealista hegeliano, Baran separa la conciencia de la naturaleza, convirtiéndola en algo absoluto y concluye que el mundo material es producto de la actividad de una conciencia que está más allá de lo humano. De este modo el concepto de totalidad no deja de pertenecer al ámbito de lo metafísico en tanto se articula, necesariamente, a lo que el mismo Hegel denominaba espíritu universal. Sin la invención de este tipo de espíritu sería imposible considerar a lo eterno o permanente en el mundo como lo primario y esencial, y a la naturaleza como lo secundario, como aquello que depende del espíritu y que por lo tanto es mutable. En esa dialéctica, el espíritu universal se convierte en la fuente que controla al mundo a partir de esa otra categoría asociada a la verdad universal: el concepto de totalidad, concepto esencial en el contexto productivo de la novela latinoamericana de los sesenta.

La totalidad o la lógica del mundo para la ideología hegeliana se corresponde con un movimiento dialéctico, entendido como un desplazamiento contradictorio propio de todos los fenómenos, tanto los sociales como los naturales que acontecen en él. Esa es la llamada dialéctica idealista que se encuentra en el horizonte de los intelectuales revolucionarios de los años sesenta. Por 
ello cuando estos intelectuales hablan de la totalidad o acogen la posibilidad de representar la totalidad en sus novelas se refieren a la posibilidad de representar al mundo en todas sus fases y niveles, desde los más irrelevantes y, aparentemente, intrascendentes, hasta los más sublimes e importantes, pero movilizados por lo que denominan las fuerzas sociales de la historia. Es este movimiento el que, para ellos engendra racionalmente a la sociedad, es este movimiento el que le da forma.

Los escritores revolucionarios de los sesenta en América Latina son hegeliano marxistas porque coinciden en aceptar que el mundo, tanto natural y social es la expresión de un proceso que supone un cambio permanente que incorpora la negación de ese mundo como una condición inevitable. En realidad, nadie hasta Hegel, había concluido en la filosofía alemana que el desarrollo histórico se concretaba en una continuidad en permanente movimiento. Si Hegel se hubiera abstenido de separar la conciencia humana de la naturaleza, no habría llegado al concepto de razón universal. En efecto, si Hegel no hubiera separado a la conciencia humana de la naturaleza, no podría haber llegado al concepto de razón universal que es la base de su idealismo objetivo y que respalda el concepto de totalidad sin el cual el mundo no podría ser comprendido.

Baran, como los materialistas dialécticos, cree en el concepto de totalidad concreta. Este concepto sirvió a los marxistas para explicar la realidad en su concreción, es decir, a partir de la relación entre los diversos objetos, sucesos, hechos y sujetos que la conforman y su conexión. Esto, desde luego, apuntaba a la comprensión racional del mundo y al propósito final de transformar la realidad.

El propósito de Baran se sustentaba en la idea que los materialistas defienden hasta hoy: la realidad es un todo estructurado, compuesto, regido por leyes que hay que descubrir y que además tiene un desarrollo en el tiempo, condición que la convierte en un proceso histórico transformable y al que, consiguientemente, debemos asignarle un fin. Por lo tanto, para el intelectual en el que piensa Baran, es un deber concebir a la realidad como una totalidad que puede y debe ser comprendida y abarcada.

La lucha del intelectual debe ser la de quien identifica en el sistema capitalista un sistema que fomenta la desarticulación y disolución de la experiencia social. De allí que considere al intelectual esencialmente como alguien que debe reconstruir y articular los componentes de la totalidad integrante del proceso histórico dentro del cual "la literatura y el arte, como la condición cultural y psíquica del pueblo, son centrales". A eso se refiere cuando sostiene que lo importante es que "el intelectual esté sistemáticamente buscando relacionar cualquier área específica en que esté trabajando con otros aspectos de la existencia humana" (1961:17). 
El intelectual debe, para Baran, además, "descubrir las relaciones complejas entre cualquier fenómeno que ocurra en un momento dado y lo que es indudablemente el centro del proceso histórico: la dinámica y la evolución del orden social mismo" (1961:17). Su tarea, en este sentido, posee una dirección clara: atender a la forma en que se producen los acontecimientos y a la relación que éstos guardan con la totalidad del proceso histórico. Esta labor es ciertamente ambiciosa y convierte al intelectual en un gran observador, en alguien con una gran panorámica de los acontecimientos y con una capacidad para interpretarlos.

Solo este mandato convierte al intelectual de los años sesenta en un sujeto responsable y con una obligación capital: construir las versiones más completas y cabales del orden social. Ahora bien, demos por descontada la gran responsabilidad que la asunción de este mandato genera en el escritor de ficción y pensemos en algo más difícil de cumplir, pensemos en el compromiso del intelectual relacionado con la obligación de responder a grandes interrogantes sociales como ¿cuál es el sentido del proceso histórico?, ¿cuál es la verdadera identidad latinoamericana? o ¿hacia dónde se dirige la sociedad? Queda, pues, bastante claro que el peso y la importancia que se le asigna al intelectual es inmensa en los años sesenta y que su identidad se va configurando necesariamente a partir de lo que la sociedad espera de él.

En perspectiva, el artículo de Baran postula que el intelectual debe desarrollar una mirada integral de la realidad, cumpliendo de ese modo con un supuesto esencial del marxismo: es posible comprender los hechos de forma racional siempre y cuando la realidad sea concebida como un todo estructurado. Sólo bajo esas condiciones cualquier hecho puede ser comprendido. Pero no solo eso. En el caso del intelectual de los años sesenta, esa se convierte, desde el campo literario, desde la ideología literaria, en la única manera de luchar contra el imperialismo. De allí a la escritura de novelas totales no hay más que un paso, dado en su momento, por los más destacados escritores del "boom".

\section{La novela moderna y la representación de la totalidad}

Habría que comenzar postulando que la novela moderna, aquella que cancela la experiencia de la narrativa del realismo naturalista y que se produce en el contexto de la vanguardia europea, contiene ya los elementos programáticos de la que luego se constituirá en el proyecto de la novela total de los escritores del "boom".

Es indudable que la experiencia revolucionaria de la vanguardia afecta al discurso de la novela alejándola del realismo ingenuo y que en el caso de nuestra narrativa, sólo puede hablarse de "nueva narrativa hispanoamericana" si se 
considera el modo en que nuestro discurso novelístico dialoga con los principios que animaron esa revolución en la que se buscó representar, sobre todo, los diversos niveles de realidad.

En este punto conviene destacar la forma en que ciertas convenciones formales del realismo son negadas por efecto de la influencia de la vanguardia y el modo en que esa negación apunta a la representación de esa ansiada totalidad. Empecemos por la concepción misma de la obra. Los nuevos narradores apuestan por la creación de un universo más permeable a la participación del lector quien, bajo este supuesto, es concebido como un constructor, como parte de la historia que es narrada. Además, a partir de la concepción de la obra abierta, los textos permiten múltiples lecturas y apuestan, mediante la explotación de símbolos y alegorías, por lo poético. De este modo se contesta a las limitaciones de realismo naturalista y se abandonan las pretensiones del determinismo causalista en su aproximación al sujeto y a su comprensión bajo los supuestos del método científico.

Con respecto al manejo de la perspectiva temporal, en principio, se renuncia a la dictadura de la cronología a favor de una narración articulada a una concepción del tiempo en la que el pasado y el presente establecen un diálogo productivo gracias al cual es posible postular una lectura de la historia. En su versión más ingenua, la narración lineal es cuestionada y reemplazada por un relato que incorpora anacronías (término con que se señala cualquier alteración en la disposición natural de los acontecimientos). La narración a través de su narrador, de este modo, adelanta o retrasa información de acuerdo a sus intereses y a los efectos de sentido que busca lograr en el lector. Así mismo, se explotan todas las posibilidades que permite el ritmo narrativo. Vemos, en efecto, una proliferación de experimentos formales basados en elipsis, pausas, sumarios, cortes, etc. cuyo objetivo es afectar la dimensión temporal y plasmar el universo interior del sujeto permeable a los pliegues del tiempo y no a su cronologización. Sumemos a todo esto la forma en que se produce la subjetivación del tiempo a través de su interiorización, activada a partir de sucesos externos a la conciencia de los personajes cuya función es dejar fluir lo que los personajes guardan en el interior.

Con respecto a la perspectiva narrativa, se emplean diversos regímenes de focalización. Tanto la exposición de la interioridad que busca la profundización en el universo íntimo de los personajes como la narración objetiva exteriorista que se limita a administrar información accesible a los sentidos, son empleadas para proporcionar al lector una representación de los diversos niveles que componen la realidad, pero también las diversas posibilidades de percibir el mundo. A este afán ayuda el empleo de técnicas como el montaje, la narración paralela, el monólogo interior, los vasos comunicantes, los diálogos simultáneos 
entre otras, técnicas que buscan alterar la convención de la linealidad narrativa y de la lógica causalista que sustentaban al realismo decimonónico.

El narrador autoritario clásico del siglo XIX, de ilimitada capacidad para referir los contenidos del mundo representado es reemplazado por la presencia de diversos narradores cuya función es relativizar la autoridad de quien se había constituido en la conciencia absoluta de la narración a partir de la cual se juzgaban los hechos y los personajes. Los nuevos narradores optan por la multiplicidad de puntos de vista y de voces narrativas.

Con respecto al tratamiento del espacio, mencionemos que no se renuncia a la exposición de espacios propios o reconocibles por la experiencia del lector. En ese sentido la vocación realista es visible en muchos narradores. Lo que sucede es que la conflictividad del personaje con su entorno (tanto social como individual) es tratada a partir de una fuerte subjetivación que incorpora la dimensión mítica y maravillosa para explicarla.

Habría que mencionar, también, la crucial importancia que tiene la exploración en las estructuras narrativas en el propósito de modernizar la novela. En este momento se puede advertir el tratamiento de recursos como la circularidad, la discontinuidad, la fragmentación, las intercalaciones, el consabido montaje, entre otras.

Por todo lo dicho, como sostiene Carlos Schwalb (2001:12) la novela moderna supone una ampliación, una expansión del horizonte de realidad que los escritores del siglo diecinueve lograron conquistar. Esta expansión supone la incorporación de nuevas áreas de experiencia a la novela cuyo propósito es ahora mostrar la diversidad del universo considerado objetiva y subjetivamente, con la presencia del discurso racional y el irracional. La presencia de discursos como el mítico, milagroso, mágico, legendario, maravilloso, fantástico evidencian el nivel real imaginario de la experiencia humana. Niveles como el social, individual, cultural, económico, político se relacionan con el aspecto real objetivo de la realidad. A partir de esta primera expansión la novela se orienta hacia la totalidad.

En segundo término, si bien la novela rompe con el pasado a partir de la fragmentación de la unidad tradicional del mundo, (Schwalb 20012), luego busca reconstituir esa unidad a partir de una lógica fragmentaria. Esto significa para Schwalb que la novela instituye un espacio no sagrado en el que las partes de la totalidad no se encuentran articuladas al discurso hegemónico de la religión. La novela moderna presentaría así un mundo complejo, fracturado, fragmentario, altamente racionalizado y analítico, filtrado por la ideología burguesa. Solo así la novela elabora una síntesis artística y crítica en donde se postula una restitución de la unidad perdida. Esta labor de síntesis demanda la creación de una perspectiva desde la cual se busca reorganizar, desde la soledad metafísica del hombre contemporáneo, el universo. Esta idea funcionará en autores como Sábato o 
Cortázar cuyos proyectos de novela precisamente apuntan a la representación de la totalidad, es decir a restituir al hombre en el centro del cosmos con el afán de devolverle, por otros medios, la unidad pérdida. Este proyecto se constituirá en la gran inspiración para la novela de occidente a mediados del siglo XX y cómo no, para la novela hispanoamericana de los años sesenta.

\section{La representación de la totalidad}

\section{El proyecto de la "novela total" hispanoamericano}

La novela total, ese ambicioso proyecto literario cuya realización supuso un gran esfuerzo creativo, encarnó en algunas de las obras de los escritores del "boom". Ejemplos notables son La casa verde de Vargas Llosa, Cien años de soledad de García Márquez o Rayuela de Julio Cortázar.

La representación de la totalidad en la novela hispanoamericana es vista desde tres puntos de vista diferentes, con sus respectivos desarrollos en el contexto de esta eclosión novelística y responde, como hemos visto, a las demandas del campo intelectual de los años sesenta.

En primer lugar tenemos a la novela metafísica de Ernesto Sábato cuyas creencias en torno de la ficción le permiten postular que la novela es el mejor instrumento para recuperar la unidad primigenia del hombre, aquella unidad con el universo, con el orden cósmico, perdida para siempre. Para que se produzca la postulación sabatiana debemos partir de una condición previa: la defectividad del ser humano, su carácter disgregado. Frente a esta condición Sábato nos habla del "hombre integral", aquel cuya esencial condición se da en su contacto con la naturaleza, con ese todo que la ideología burguesa terminó de disgregar.

Sábato considera que solo la novela es capaz de realizar esa síntesis debido a que un discurso como el filosófico estaría limitado por su carácter racional conceptual. Citémoslo:

"La filosofía, por sí misma, es incapaz de realizar la síntesis del hombre disgregado: a lo más puede entenderla y recomendarla (...). La auténtica rebelión y la verdadera síntesis no podía provenir sino de aquella actividad que nunca separó lo inseparable: la novela (...) En esta novelas cumbres se da la síntesis que el existencialismo fenomenológico recomienda. Ni la pura objetividad de la ciencia, ni la pura subjetividad de la primera rebelión: la realidad desde un yo; la síntesis entre el yo y el mundo, entre la inconsciencia y la conciencia, entre la sensibilidad y el intelecto (1981:20).

Para Sábato la novela es por naturaleza híbrida, esta condición, sostiene, le da un destino y una función: integrar. Esta es la ventaja que posee la novela, solo ella puede reintegrar al yo con el mundo, a la consciencia con la inconsciencia, a la sensibilidad con el intelecto. 
En segundo lugar tenemos al proyecto de la novela ontológica de Julio Cortázar. El autor postula que la novela debe pasar a convertirse en un instrumento de salvación del ser humano. La idea es que, como instrumento de salvación, la novela asuma el compromiso de mejorar la condición humana cuyo resultado beneficie al hombre. Por eso sus novelas bucean en la conciencia de sus personajes cuyo viaje interior es una experiencia que convoca lo religioso, lo lúdico, lo azaroso, la mítico, lo maravilloso, lo fántastico.

En tercer lugar tenemos a la novela total de Vargas Llosa. Se trata, según el autor, de "abrazar una realidad en todas sus fases", en todos sus niveles. Lo central de este proyecto se sustenta, según J. M. Oviedo, en la siguiente tesis: "La novela total es el instrumento plural para hallar la verdad esencial de lo existente, del hombre y de la materia". Aquí es evidente la relación entre la concepción hegeliana de la verdad como totalidad y la novela como el espacio privilegiado para su representación.

Las novelas, así, deben cumplir con representar niveles como el sensorial, el místico, el mítico, el maravilloso y el onírico. La idea es que mientras más niveles se encuentren comprometidos, más posibilidades de alcanzar la verdad, ese objeto elusivo y atractivo que alentaba a los escritores del "boom" a postular universos ambiciosos en sus novelas. Un ejemplo de ese intento totalizador para Vargas Llosa es, pues, Cien años de soledad a la que califica del siguiente modo: "Es una novela total por su materia, en la medida en que describe un mundo cerrado, desde su nacimiento hasta su muerte y en todos los órdenes que lo componen -individual, colectivo, legendario, histórico, cotidiano, místico- y por su forma, ya que la escritura y la estructura tienen como la materia que trata en ellas, una naturaleza exclusiva, irrepetible y autosuficiente" (2007: XXVI).

\section{Vargas Llosa, lector de la "totalidad" en Cien años de soledad}

Cuando en 1967 se publica Cien años de soledad, el campo literario hispanoamericano se encuentra preparado para recibir, como se debe, a esa proeza de nuestra literatura. Claudia Gilman sostiene que "la irrupción de Cien años de soledad es la señal más evidente de la fortaleza de nuestro campo literario constituido entre 1959 y 1967" (2003: 98). Ya en ese momento nuestra crítica trabaja claramente con conceptos como totalidad concreta o intento totalizador, y reconoce que nuestros escritores han logrado consolidar una nueva manera de escribir novelas, asociada a la expresión de lo maravilloso y mágico de nuestro continente. De hecho, la novela del colombiano fue presentada como modelo de lo que debería ser la ficción literaria entre nosotros, en la medida en que 
atendía o daba, como sostuvo García Ascot con la "intuición ontológica del ser hispanoamericano". Cien años de soledad, dice Claudia Gilman, "se consideró summa y metáfora de la totalidad latinoamericana y de todas las totalizaciones posibles: era la ficción modélica de la verdadera literatura universal producida en el continente" (2003: 101).

Coincidiendo con en este estado de entusiasmo y admiración, la publicación de su libro Historia de un deicidio (1971) sobre la obra narrativa de Gabriel García Márquez, muestra el interés de Vargas Llosa por ordenar, por primera vez, la obra del colombiano y por otorgarle consistencia teórica al proyecto de la novela total que su gran novela expresaba como ninguna otra hasta ese momento. El libro de Vargas Llosa muestra, también, la claridad de objetivos y la consistencia de nuestro campo literario con respecto a la necesidad de reconocer y proyectar universalmente la obra de García Márquez, reconocimiento que también se buscaba para la narrativa del continente, a partir de su estudio y elogio, en ámbitos como el español, en donde es publicado el libro.

Para comenzar, es evidente que a Vargas LLosa le interesa la estrategia empleada por el colombiano para la "edificación" de su novela. La constatación de que Cien años de soledad integra en una "síntesis superior" a personajes, espacios y acciones presentes en sus ficciones anteriores obliga a Vargas Llosa, y a cualquier lector, a reparar en un hecho: García Márquez emplea la dialéctica materialista al momento construir su novela. En efecto, Cien años de soledad cumple con el más esencial de los principios de la dialéctica: buscar la articulación las partes de un todo que se va constituyendo como tal con el objetivo de postular una totalidad. El objetivo, lo reiteramos, es lograr la articulación de las partes dispersas en sus cuentos y novelas de modo que estos fragmentos-fenómenos queden perfectamente integrados en una unidad, en ese libro-mundo que es Cien años de soledad. Este hecho parte, desde luego, del reconocimiento previo de esa unidad a la que pertenecen, en tanto esa unidad se concibe como un todo estructurado, pero que se percibe fragmentado y que por lo tanto es necesario reconstituir. La idea de la síntesis superior, pues, se sustenta en una concepción materialista dialéctica del mundo sin la cual sería imposible plasmar, en esos términos, la realidad.

Para Vargas Llosa Cien años de soledad cumple con dos objetivos relacionados también con una visión dialéctica de la realidad. El primer objetivo tiene que ver con el hecho de que la novela agota la materia que trata, es decir que narra un mundo que consume y aprovecha su propia materia en todos sus matices. El segundo objetivo cumple con el hecho de que la novela misma se agote o finalice con ese mundo, es decir, que lo destruya al final y se destruya simbólicamente a sí misma. A partir del cumplimiento de estos dos objetivos puede advertirse otra de las ideas fuerza que rige la novela, esto es, la idea de que al cerrarse sobre sí 
mismo, después de haber cumplido un ciclo histórico, el mundo representado en la novela ha atravesado necesariamente diversas etapas de desarrollo social cuyas inevitables contradicciones, previsiblemente, llevaron a ese mundo a su propio fin, a su destrucción. De esta forma la novela cumple, desde el punto de vista histórico, con la perspectiva materialista, pues es evidente que en Cien años de soledad las relaciones de producción, a través de las cuales se desarrolló el sistema social macondiano, han evolucionado hacia un cruel capitalismo, es decir, se han tornado absurdas e injustas haciendo insostenible el orden que se encuentra detrás de esas relaciones. Cuando eso sucede en la novela, la continuidad histórica se hace irracional y se torna inconducente seguir sosteniendo ese mundo injusto. Por ello, al concluir la novela, se da paso a la destrucción, a la negación de ese mundo, como sostiene la dialéctica.

En otro nivel, para Vargas Llosa, Cien años de soledad es dialéctica porque encierra en sí misma algunos valores cuya articulación antinómica propende a un diálogo que implica, para su realización, un vasto campo de expectativas, todas ellas vinculadas a esa ambicioso proyecto de alcanzar la totalidad. Por ello, por ejemplo, la novela puede dialogar con la tradición sin renunciar a esa modernidad que también la caracteriza, y puede proyectarse al amplio campo de lo universal sin renunciar a ser regional y hasta local, incluyendo el hecho de ser realista y mágica a la vez.

De otro lado, es en el plano de la historia en donde Vargas Llosa postula a la novela del colombiano como la máxima expresión de esa ambicionada totalidad. En principio, dice, la "novela trabaja una materia que narra la historia completa de un mundo desde su origen hasta su desaparición" (2007: XXVI). El proyecto de construir esa completud, ese mundo cerrado, se articula a la necesidad que Paul Baran reclamaba a los intelectuales de entonces: brindar interpretaciones cabales del proceso histórico tratando de referir todos los aspectos de la vida comprometidos en el mundo representado. La novela de García Márquez cumple, desde su concepción, con la tarea de sintetizar imaginariamente, de ofrecer una imagen compacta de la historia latinoamericana en un arco de cien años en los que se concentran los hechos más relevantes de su devenir, desde su ingreso a la historia, como lo califica Vargas Llosa, hasta su extinción. En efecto, en Cien años de soledad es posible describir las transformaciones sufridas por el pueblo de Macondo, desde el momento que sale de su aislamiento, debido a una ruta que rompe con el cerco de la ciénaga que lo limitaba en su comunicación con el mundo exterior, hasta la decadencia del pueblo, cuando la compañía bananera lo abandona. En este arco de cien años está bien descrita la forma como se da la penetración del capitalismo en nuestro continente y la colonización de nuestra economía y las luchas de quienes se oponen a esa penetración. Queda, pues, bien descrito el universo latinoamericano como un universo subdesarrollado 
en el que el horizonte social de Macondo se muestra bajo el control del viejo patriarcalismo, representado por la familia de los Buendía.

La novela cumple también con representar la totalidad de la escala social a través de personajes que, sin dejar de ser únicos y hasta singulares, se proyectan en la sociedad del texto como muestras de una clase o fracción social. Las demandas de una representación que no oculte la evidente segmentación social de los países latinoamericanos se halla respaldada por el juego de jerarquías sociales planteado en Cien años de soledad. En efecto, en ella es visible el hecho de que los Buendía representan al segmento social criollo de las clases latinoamericanas desde el momento que encarnan el paradigma patriarcal conservador que los aísla de los demás grupos o cuando se visibiliza una relación vertical entre ellos y los sirvientes cuya condición étnica es siempre indígena o guajira.

Esta dinámica que plantea un tipo de aislamiento social de carácter insolidario es la razón del fracaso de las burguesías tradicionales y su imposibilidad de comprender la totalidad del proyecto social como un proyecto de alianzas solidarias e igualitarias. A este carácter cerrado de la experiencia social protagonizado por los Buendía, debemos sumar el contradictorio modo, dialéctico por cierto, a través del cual se caracteriza a los primeros integrantes de la familia. Recordemos que los hijos del patriarca, José Arcadio y Aureliano, están cada premunidos de una virtud que, por separado, los imposibilita de llevar adelante el proyecto de salvación de la estirpe: por un lado tenemos a la razón gobernando la mente de Aureliano, pero despojado de voluntad y por el otro a Arcadio con la fuerza necesaria para vencer los más grandes obstáculos, pero entregado a la irracionalidad más inconsecuente. Esta forma de caracterización de los personajes en la que uno es el reverso del otro o su opuesto y en la que se les atribuye o despoja de una cualidad notable, será determinante para lograr una gran riqueza de seres humanos cuya amplitud y presencia logra construir un fresco social bastante ambicioso y totalizador. Como es visible en la novela, tenemos comerciantes, sirvientes, soldados, forasteros, etc.

Un último aspecto de la totalidad que Cien años de soledad contempla y que es destacado por Vargas Llosa está relacionado con el papel que lo imaginario juega en la novela. A partir de las posibilidades de lo imaginario y de los planos que posibilita, la novela logra evidenciar el carácter pre moderno de las mentalidades sujetas a un tipo de orden patriarcal. En el universo propuesto por la novela lo mágico, lo milagroso, lo mítico legendario y lo fantástico cumplen varias funciones. Quizá la primera de las funciones tenga que ver con la denuncia de ese mundo en el que los prejuicios y las supercherías están entronizados en el comportamiento de quienes, como clase, nunca consiguieron articularse, desde su condición gradualmente burguesa, a un proyecto de desarrollo capitalista propio. 


\section{Conclusión}

El proyecto de la novela total se consolida en el contexto de los años sesenta en Hispanoamérica sobre la base de las demandas del campo intelectual, gobernado por urgencias de índole política, urgencias relacionadas con la necesidad del cambio social que impregnan el campo del arte en general. De este modo, desde el campo intelectual el campo literario articula un elenco de preocupaciones cuyo destino final es el espacio de la novela, preparada entonces, como ningún otro género literario, para explorar en cuestiones como la identidad latinoamericana o la construcción de una patria continental finalmente liberada de las dictaduras y del imperialismo.

El proyecto de la novela total no se concibe sin la existencia de la figura del intelectual comprometido. El compromiso como tal supone la aceptación, a su vez, de los principios de la dialéctica materialista sin la cual es imposible comprender el concepto de totalidad concreta, categoría que implica un acercamiento científico a la realidad y que los escritores de los años sesenta trasladan al campo de la representación novelística para llegar, a su modo, a una representación de la verdad, esa verdad que entonces se oponía a la visión burguesa y fragmentada de la realidad.

El proyecto de la novela total halla su máxima expresión en un texto como Cien años de soledad cuya "edificación”, según Vargas Llosa, se realiza según los patrones de la dialéctica materialista, alimentada por una concepción totalista del mundo cuya puesta en funcionamiento en una novela busca integrar, en un todo, que se presupone comprensible y sobre todo accesible, los fragmentos dispersos de una realidad, atendiendo a todos sus niveles posibles, contemplados en los planos de lo imaginario y de lo real objetivo.

El proyecto de la novela total se realiza plenamente sobre un horizonte histórico que, desde una perspectiva materialista, permite advertir el nacimiento, auge y destrucción de un mundo, como en Cien años de soledad de Gabriel García Márquez.

\section{Referencias bibliográficas}

BARAN, Paul (1961). "El compromiso del intelectual” en Revista Casa de las Américas, 7; pp. 14-21.

BOURDIEU, Pierre (1995). Las reglas del arte. Génesis y estructura del campo literario. Barcelona, Anagrama.

BOURDIEU, Pierre (2003). "Campo intelectual y el proyecto creador" en Campo de poder, campo intelectual, Buenos Aires, Editorial Quadrata; pp. 13-52.

GILMAN, Claudia (2003). Entre la pluma y el fusil. Debates y dilemas del escritor revolucionario en América Latina. Buenos Aires, Siglo XXI editores Argentina s.a. 
WittGenstein y La teoría Contemplativa del significado. Observaciones a la tesis de Juan Abugattás

RAMA, Ángel (1964). "Diez problemas para el novelista latinoamericano”. Casa de las Américas, 26; pp. 4-43.

RODRÍGUEZ MONEGAL, Emir (1972). El "boom” de la novela latinoamericana. Caracas, Editorial Tiempo Nuevo.

SABATO, Ernesto (1981). El escritor y sus fantasmas. Barcelona, Seix Barral.

SCHWALB, Carlos (2001). La narrativa totalizadora de José María Arguedas, Julio Ramón Ribeyro y Mario Vargas Llosa. New York, Peter Lang editores.

VARGAS LLOSA, Mario (2007). "Cien años de soledad. Realidad total, novela total” en Cien años de soledad. Edición conmemorativa. Colombia, Real Academia Española, Asociación de Academias de la Lengua Española; pp. XXV-LVIII. 